\title{
Developmental Anatomy and Features of the Exocarp as Related with Fruit Skin Disorders in 'Niitaka' Pear Fruit
}

\author{
Yoon-Pyo Hong ${ }^{1}$, Seung-Koo Lee ${ }^{2}$, Youn-Moon Park ${ }^{3}$ and Hee-Seung Park ${ }^{4 *}$ \\ ${ }^{1}$ Postharvest Technology Division, National Horticultural Research Institute, Suwon 440-706, Korea \\ ${ }^{2}$ Dept. of Horticulture, Seoul National University, Seoul 151-742, Korea \\ ${ }^{3}$ Dept. of Food Science, Andong National University, Andong 760-749, Korea \\ ${ }^{4}$ Dept. of Applied Plant Science, BET Research Institute, Chung Ang University, Anseong 456-756, Korea
}

\begin{abstract}
Causal process and characteristics of three physiological disorders on 'Niitaka' pear fruit was analyzed through an anatomical approach. Anatomical differences in the skin layers suffered from surface-stain, skin-blackening, and peeling-off disorders were observed and analyzed using microphotography. The skin layer of surface-stain fruit was $11.6 \mu \mathrm{m}$ thicker than that of sound fruit. The thicker skin layer of surface-stain fruit seemed to be resulted from the formation of two or three cork cell layers. In contrast, the fruit skin of skin-blackening suffered fruit was $95.8 \mu \mathrm{m}$ thinner than that of sound one. The thinner skin layer of skin-blackening fruit was induced by the collapse of the hypodermal layer. The third disorder, peeling-off symptom was characterized by a newly developed decorking layer beneath the cork cell layer. The developmental process of decorking leading to peelingoff consisted of reactivation of phellogen, vertical elongation of phellogen cells, and physical force up to the cork layer. The term, decorking was first suggested to describe anatomical process of peeling-off disorder.
\end{abstract}

Key Words: epidermis, hypodermis, peeling-off, skin-blackening, surface-stain.

\section{Introduction}

Various disorders on the fruit surface have been observed in 'Niitaka' pear fruits among which surfacestain, skin blackening, and peeling-off symptoms (refer to Fig. 1) are frequently occurred during storage period. Most researches on the postharvest disorders in oriental pears were focused on the elucidation of biochemical causes and anatomical aspects of skin-blackening disorder, whereas only few reports are available on the other two disorders.

Surface-stain disorder is sometimes observed on the tree but generally occurs during storage period. The typical symptom of the disorder is irregular, grayish discolored blotch on the surface. Despite enormous economical loss by depreciation of marketability, causal factors of the disorder and preventing methods have not been fully provided, yet. Surface-stain tends to occur more when fruit are harvested at advanced maturity, delayed before storage, and stored under high ethylene environment (Hwang et al., 2003). As for the inducing factor of the discoloration, Yun et al. (2000) proposed

Received; January 2, 2008. Accepted; April 8, 2008.

* Corresponding author (E-mail: koussa@cau.ac.kr). that fungi might take part in the injury occurrence. In contrast, Hwang et al. (2003) suggested that fungi infection could be secondary cause of the discoloration after primary suffering from a certain physiological disorder.

Skin-blackening disorder is a kind of browning symptom from the biochemical points of view. The color of the suffered area looks black rather than brown, thus the disorder is called skin-blackening. Discolored area is slightly sunken and spreads over the surface in an irregular shape from a few square millimeters to the entire fruit skin. The inducing mechanism is explained as the oxidation of polyphenol compounds by polyphenol oxidase (PPO) in fruit (Costeng and Lee, 1987; Wu et al., 1992). During the biochemical process, polyphenol is oxidized to quinone which is further polymerized to make brown, red, and black pigments (Jean-Jacques et al., 1990; Mori et al., 1965). Incidence of skin-blackening disorder seemed to be influenced by preharvest and postharvest factors such as genetic factors, cultural techniques, and storage conditions could make the appearance of the skin disorders (Lurie et al., 1991; Wills and Scott, 1982; Yamazaki et al., 1988). Interesting observation was a remarkable increase in the incidence of the disorder when fruit were stored at low temperature 


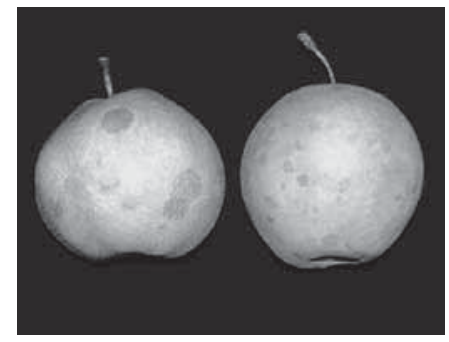

Surface stain

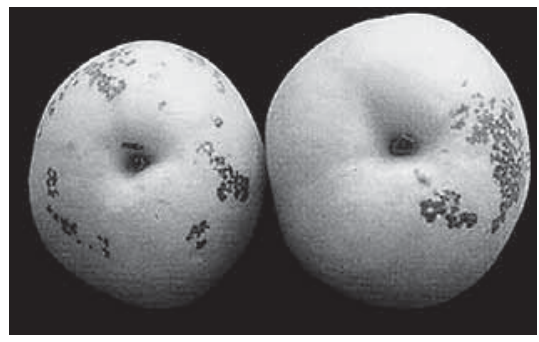

Skin blackening

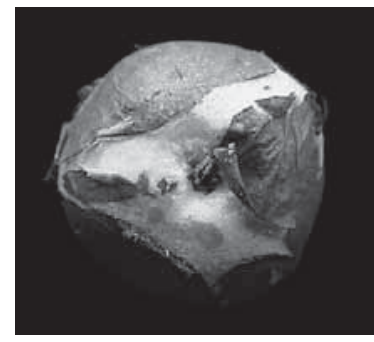

Peeling-off

Fig. 1. Typical symptoms of three different skin disorders observed in 'Niitaka' pear fruit during storage.

immediately after harvest without preconditioning at ambient temperature. However, the primary cause why polyphenol oxidation occurs in a certain fruit and under specific storage procedure is still unknown. Anatomical approaches to find out the source tissue of discoloration have provided two different viewpoints: collapsed and crumpled parenchyma tissue cells (Park and Kwon, 1999 ) and disruption of epidermal cells (Kang and Lee, 2003).

Peeling-off symptom on 'Niitaka' pear fruit is usually observed after long-term storage, especially under severe temperature fluctuation condition (Hong, 2002). The biochemical cause and inducing mechanism of the disorder have not been clearly established, yet.

The objective of the present study is to discriminate between three different surface disorders and to elucidate developmental processes of the peeling-off disorder from anatomical points of view.

\section{Materials and Methods}

'Niitaka' pear fruits were collected in 2001 to 2003 harvest seasons from the orchard located in Anseong region, Korea and stored in refrigerated cold rooms. Anatomical characteristics of surface-stain and skinblackening disorders were observed on the suffered fruit during the storage, while features of peeling-off disorder were observed on the developmental stages using fruit samples obtained during 100 to 120 days of storage.

In addition, skin structure of artificially-induced skinoff symptom was observed to distinguish anatomical changes from peeling-off disorder. Artificial induction of skin-off symptoms was achieved by packaging plastic container with $30 \mu \mathrm{m}$ low density polyethylene film and storing under refrigerated condition at $0^{\circ} \mathrm{C}$.

For optical microscopy, tissue samples were obtained through horizontal excision along the equator part of entire fruit. The sections were initially fixed in the $2.5 \%$ glutaraldehyde fixative for 90 minutes and then rinsed four or five times at 15-minute intervals. The sample sections were fixed for the second time with $1 \%$ osmic acid and rinsed four or five times at 20-minute intervals. The fixed sample pieces were dehydrated in the alcohol series stepwise for five minutes in each concentration followed by propylene oxide treatment. Then, individual sample disk was laid in a silicon mold at the condition of $60^{\circ} \mathrm{C}$ with epon+D.M.P. 30 for 4 days. The embedded sample was microtomed $1.5 \mu \mathrm{m}$ thick using an ultramicrotome (Ultracut R. Leica Co., Austria). Microtomed sections were stained in Schiff's reagent and observed under optical microscope (Axioskop 2. Karl Zeiss Co., Germany) (Park, 1995).

The samples for transmission electron microscope (TEM) were prepared with the same procedure as that for optical microscopy and later placed on grid as $80 \mathrm{~nm}$ thickness using an ultra-microtome. Microtomed samples were treated with uranyl acetate for 10 minutes and rinsed with distilled water, stained through 10 minutes' treatment of lead citrate and rinsed with distilled water. After all the preparation process including drying, the sample was examined under transmission electron microscope (TEM) (MEO 906E, Karl Zeiss Co., Germany).

Assessment of the number of the cell layers and cell dimension was performed using microphotographs. Fifteen representative replicates were selected and examined to count cell layers and measure cell dimensions.

\section{Results and Discussion}

\section{Anatomical characteristics of three types of postharvest fruit skin disorders}

Microscopic examination on the surface-stain suffered fruit showed thickening of the skin layers. The thickness of the suffered skin, cork cell layers plus hypodermal cell layers, was $166.0 \mu \mathrm{m}$, which was about $10 \mu \mathrm{m}$ thicker than that observed in sound fruit as $154.4 \mu \mathrm{m}$ (Table 1, Fig. 2A, B). The thicker skin tissue might be resulted from the newly formed two or three cork layers in the suffered epidermis. As related to the discolored blotch of the disorder, other studies of surface anatomy suggested that the disorder usually occurred concomitantly with fungi infection (Hong, 2002; Yun et al., 2000). If it were so, the increase in the number of cork cell layers might have been the result of a curing process or a defensive mechanism against external infection (El Hadidi, 1969; Lipetz, 1970; Morris and Mann, 1955; Struckmeyer and Riker, 1951).

Unlike the skin layer on surface-stain suffered fruit, 
thickness of skin-blackening suffered fruit was $58.6 \mu \mathrm{m}$, which was considerably thinner than that of sound fruit (Table 1). The thinner skin layers might result from the breakdown of hypodermal cells. In contrast, one layer assumed to be the cork cambium did not experience the morphological change except disappearance of tannin (Fig. 2C). Hypodermal cells seemed to be mechanically compressed with dehydration process and filled with tannin-like substances. In this occasion, the cells eventually collapsed by the destruction of the vacuole. As the result, browning process might be initiated by the bonding of the substances in vacuole and the enzymes in cytoplasm. Kang and Lee (2003) reported similar result that the hypodermis of skin-blackening suffered fruit was completely collapsed and crumpled. In contrast, Park and Kwon (1999) stated that skin-blackening symptom was not directly due to the collapse of hypodermal cell layer but to the breakdown of the

Table 1. Anatomical dimension of epidermal and hypodermal cell layers.

\begin{tabular}{lcc}
\hline \hline \multicolumn{1}{c}{ Disorder type } & Thickness of skin $(\mu \mathrm{m})$ & Number of cork cell layer \\
\hline Sound & $154.4 \mathrm{c}^{\mathrm{z}}$ & $4.2 \mathrm{~b}$ \\
Surface stain & $166.0 \mathrm{~b}$ & $6.8 \mathrm{a}$ \\
Skin blackening & $58.6 \mathrm{~d}$ & $3.2 \mathrm{~b}$ \\
Peeling-off & $247.6 \mathrm{a}$ & $0.0 \mathrm{c}$ \\
\hline
\end{tabular}

${ }^{\mathrm{z}}$ Mean separation within columns by Tukey's multiple range test, $5 \%$ level.
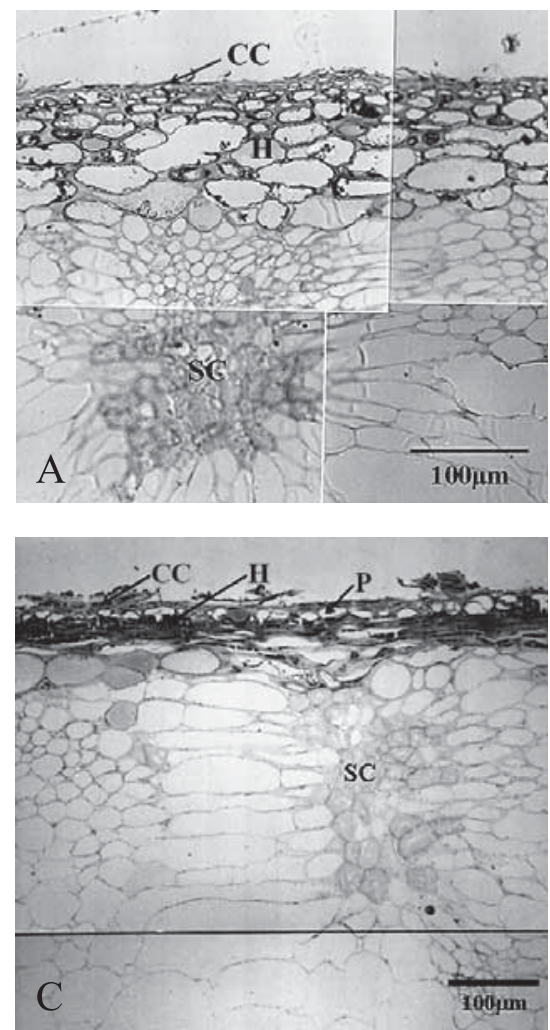

parenchyma cells underneath hypodermis. The present study confirmed the fact that skin-blackening is the result of structural deformation of hypodermal cells probably caused by environmental stress.

Pericarp structure of peeling-off suffered fruit was remarkably different from the normal tissues. The cork cell layers were partly sloughed off (Fig. 2D) or completely peeled off with the rupture of the phellogen layer (Fig. 3D). Distinct elongation of the phellogen cells was observed in the suffered fruit portion.

\section{Anatomical process and histological characteristics as} related to peeling off disorder

The first process of peeling-off might be the reactivation of phellogen cells. At the initial stage of peeling-off development after 100 days of storage, enlarged and peripherally positioned phellogen cells appeared underneath the cork layer (Fig. 3B). At this stage, tannin seemed to disappear in the reactivated phellogen cells.

In the mid stage of the disorder development observed after 110 days of storage, phellogen cells showed dramatic elongation (Fig. 3C). Most elongated cells had little tannin and the upper and lateral cell wall became much thinner except the lower cell wall that contact to hypodermis. Similar cells had been observed in periderm of Rhododendron maximum, a kind of azalea, and named as pseudo-cork cell (Esau, 1977). This investigation confirmed the pseudo-cork cell as the cork-detaching
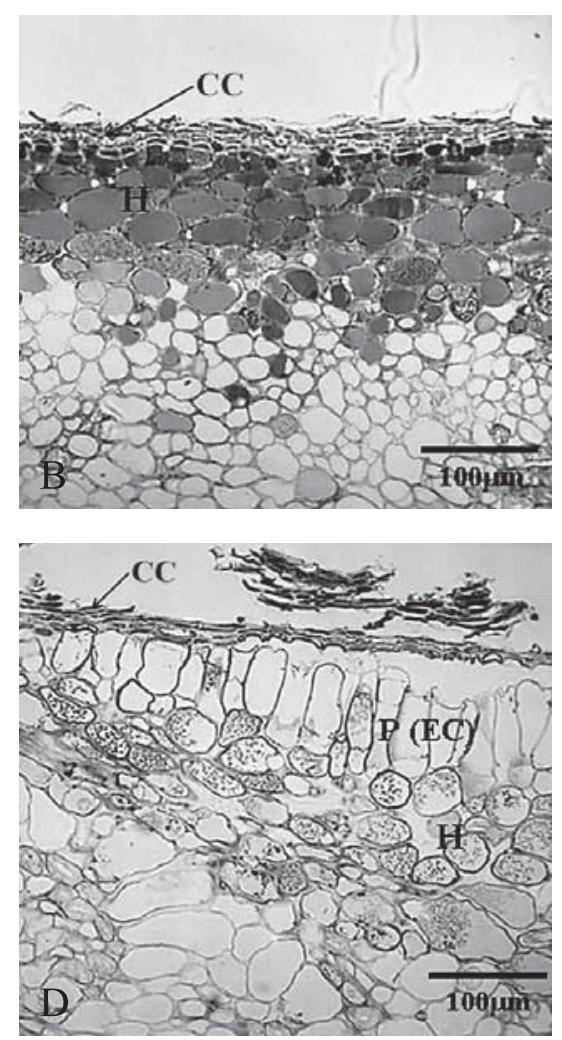

Fig. 2. Anatomical structure of sound (A), surface-stained (B), skin-blacking (C), and peeling-off symptom (D) tissues on 'Niitaka' pear fruit skin. CC, cork cell; H, hypodermis; P, phellogen; P (EC), phellogen (Elongated cell); SC, stone cell. 


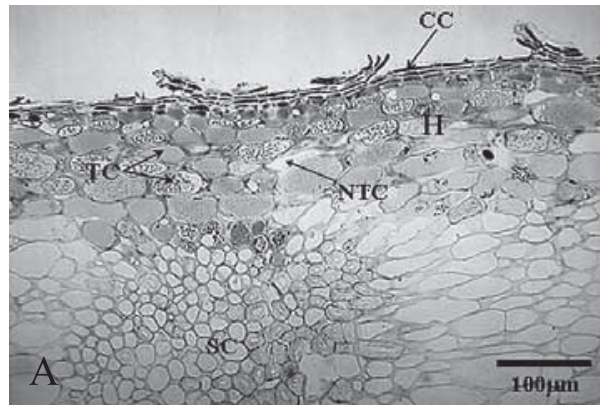

Before the initiation of the disorder

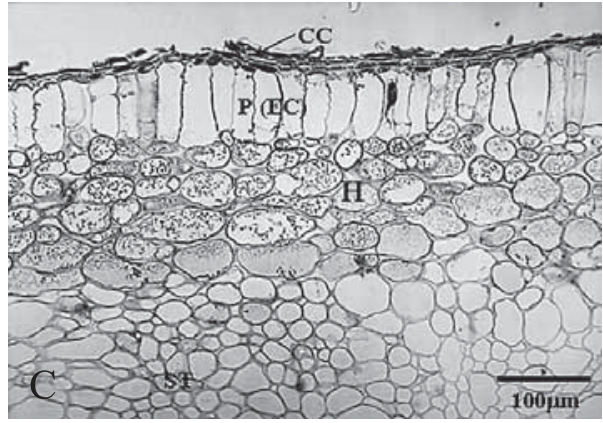

Mid stage

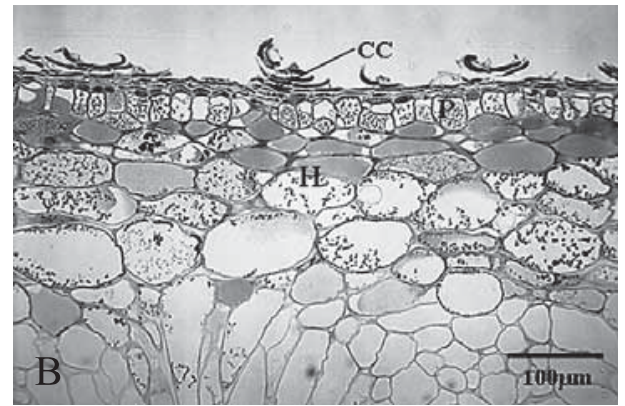

Initial stage

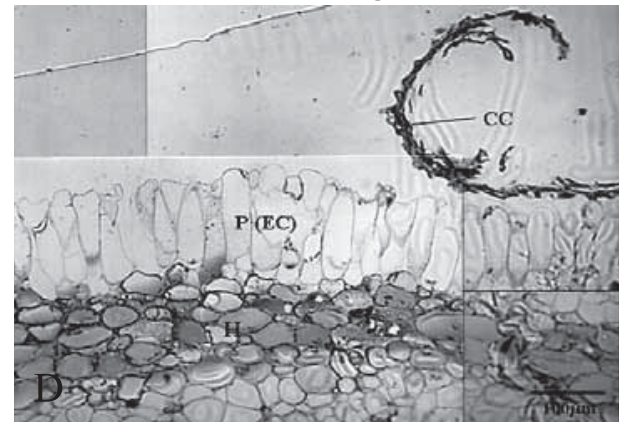

Final stage

Fig. 3. Developing procedure of peeling-off disorder on 'Niitaka' pear from harvest to 120 days of storage. A: harvest time on 'Niitaka' pear fruit skin; B: initial stage on peeling-off disorder; C: mid stage on peeling-off disorder; D: final stage on peeling-off disorder. CC, cork cell; H, hypodermis; NTC, non-tannin cell; P, phellogen; P (PE), phellogen (elongated cell); SC, stone cell; TC, tannin cell.

layer, and it was observed that cork cambium was transformed into pseudo-cork.

Figure 3D indicates the final stage of the peeling-off process with complete removal of the whole cork layer, which was observed approximately 20 days after the initiation of the disorder. The process of peeling-off symptom was described as the decorking procedure implying that peeling-off disorder was not simply a mechanical skin-off process but a more subtle separating procedure including physical force derived from the anatomical changes in cork cambium cells.

Interestingly different anatomy was obtained from artificially-induced skin-off symptoms. Skin-off symptom has been usually observed during packinghouse operation, especially when water condensation occurs on the fruit after long-term storage. Immediately after storage, the fruit seems to be normal under naked eye observation. During packing house operation, however, fruit show skin-off symptom even by a soft hand touch. Microscopic observation on the artificially-induced skinoff fruit did not show any changes in cell morphology of the skin tissues (Fig. 4). Comparison of tissue anatomy between peeling-off (Fig. 2, 3) and skin-off symptoms (Fig. 4) clearly suggested that incidence of decorking process (peeling-off) is due to the cork cambium elongation, which forces up the outermost cork layer.

Transmission electron microscopy (TEM) provided cellular level changes during the cell elongation and following peeling-off process as related to the cell wall degradation (Fig. 5). In sound fruit, the cell wall structure

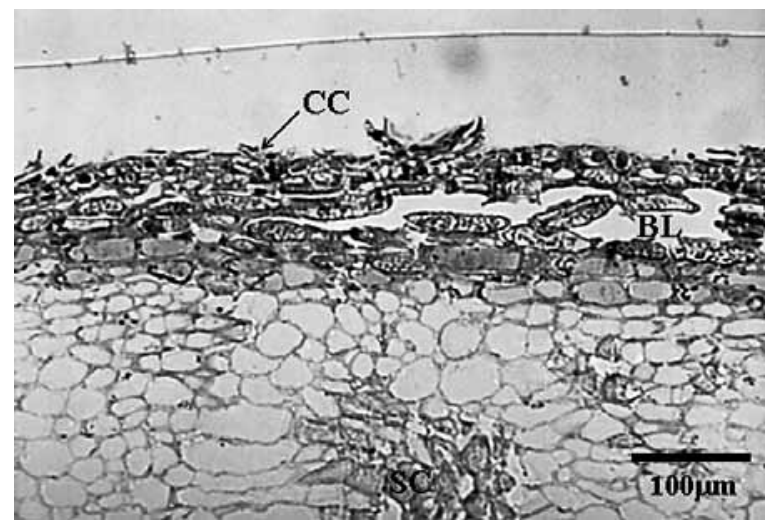

Fig. 4. Anatomical structure of the skin tissue on 'Niitaka' pear fruit suffered from artificially-induced skin-off disorder. BL: broken layer; CC: cork cell; SC: stone cell.

of phellogen remained thick and well integrated (Fig. 5A). In contrast, suffered fruit showed cell wall degradation. Based on the middle lamella position as the boundary of the cell walls between the two adjacent cells, the cell wall in the cork cell (positioned above phellogen) remained intact even in suffered fruit, whereas, the cell wall of the phellogen, the elongated cells, appeared to be completely degraded (Fig. 5B) and thinned (Fig. 5C). Elongation of phellogen cells and breakdown of the bridge between the phellogen and cork cells seemed to be two major events leading to the slough-off of the cork cell layers. It is well documented that cell wall degradation by the breakdown of pectic 

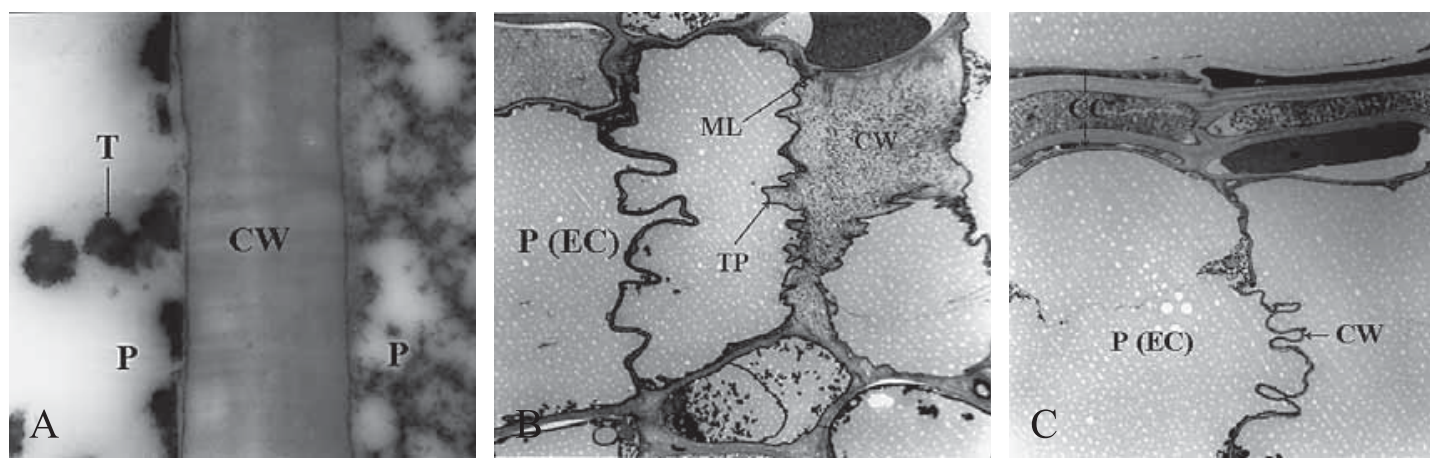

Fig. 5. Transmission electron micrograph of the sound $(A, \times 27,800)$, collapsed $(B, \times 1,670)$ and the thinned cell wall $(C, \times 1,670)$ in peeling-off disorder of 'Niitaka' pear. CC, cork cell; CW, cell wall; ML, middle lamella; P, phellogen; P (EC), phellogen (elongated cell); TP: tonoplast.

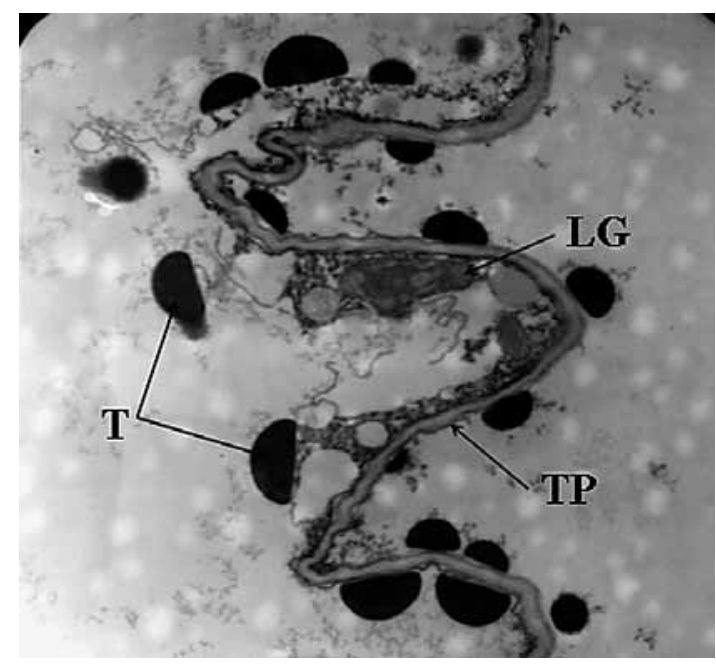

Fig. 6. Transmission electron micrograph of the condensed tannin combined with tonoplast in peeling-off disorder of 'Niitaka' pear $(\times 7,750)$. LG, lipid globule; T, tannin; TP, tonoplast.

substances occurs when fruit tissues are destroyed or during the flesh softening (Chitarra et al., 1989; Glenn and Poovaiah, 1990; Gross, 1984). TEM observation indicated that the cell wall degradation during the peeling-off process might result from the similar biochemical process as in the flesh softening since any destruction of the cell layers was not involved.

In the elongate cells, the disappearance of tannin in the vacuole occurred simultaneously with the degradation of the cell wall. The cells organizing fruit skin generally included tannin with few exceptions. The existence of tannin could be used as an indicator for discrimination between tissues of the flesh and skin. It was generally accepted that tannin in fruit skin repeated polymerization and disintegration in the course of fruit development. Disintegration of tannin substances occurs from two sites: from the central part of vacuole and from the tonoplast (Park, 1995). In the deformed cell, it was observed that tannin disintegration occurred only from the central part of vacuole and, as the result, the tannin combined with tonoplast was existed only (Fig. 6).

In conclusion, surface-stain and skin-blackening disorders seemed to have different source of discoloration process. Surface-stain disorder might be caused by the increase in cork layers, whereas skin-blackening resulted from the necrosis of the hypodermal layers. Development of peeling-off disorder, named as decorking in the present study, was caused by the elongation of the phellogen cells beneath the cork layer.

\section{Literature Cited}

Chitarra, A., J. Labavitch and A. Kader. 1989. Canning-induced fruit softening and cell wall pectic solubilization in the 'Patterson' apricot. J. Food Sci. of Publ. Inst. Food Technol. 54: 990-992.

Costeng, M. Y. and C. Y. Lee. 1987. Changes in apple polyphenol oxidase and polyphenol concentration in relation to degree of browning. J. Food Sci. 52: 985-989.

El Hadidi, M. N. 1969. Observations on the wound-healing process in some flowering plants. Mikroskopie 25: 54-69.

Esau, K. 1977. Anatomy of seed plants. 2nd Ed., John Wiley \& Sons Inc., New York.

Glenn, M. and B. Poovaiah. 1990. Calcium-mediated postharvest changes in texture and cell wall structure and composition in 'Golden Delicious' apple. J. Amer. Soc. Hort. Sci. 115: 962 968.

Gross, K. 1984. Fractionation and partial characterization of cell walls from normal and non ripening mutant tomato fruit. Physiol. Plant. 62: 25-32.

Hong, Y. P. 2002. Causal factors of fruit skin disorders during cold storage of pear (Pyrus pyrifolia cv. Niitaka) and their postharvest control (In Korean with English summary). Ph. D. Thesis. Seoul National Univ., Seoul.

Hwang, Y. S., Y. L. Pyao and J. C. Lee. 2003. Potential factors associated with skin discoloration and core browning disorder in stored 'Niitaka' pears. J. Kor. Soc. Hort. Sci. 44: 57-61 (In Korean with English abstract).

Jean-Jacques, M., A. Fleuriet and J. Billot. 1990. Fruit phenolics. CRC Press, Inc., Boca Raton, FL.

Kang, H. K. and S. K. Lee. 2003. Effects of prestorage treatment by EDTA-Ca and heating on skin blackening and quality during cold storage in 'Niitake' pear fruits. J. Kor. Soc. Hort. Sci. 44: 52-56 (In Korean with English abstract).

Lipetz, J. 1970. Wound healing in higher plants. Internatl. Rev. Cytol. 27: 1-28.

Lurie, S., J. D. Klein and R. B. Arie. 1991. Prestorage heat treatment delays development of superficial scald on Granny Smith apples. HortScience 26: 166-167. 
Mori, M., Y. Harada and Y. Tsuboi. 1965. Studies on the enzymatic browning during cold storage of white flesh colored peaches. I. Changes in polyphenolic compounds with maturities and the characteristics of polyphenol oxidase. J. Jpn. Food Sci. 12: 88-94.

Morris, L. L. and L. K. Mann. 1955. Wound healing, keeping quality, and compositional changes during curing and storage of sweet potatoes. Hilgardia 24: 143-183.

Park, H. S. 1995. The pericarp of normal and shot berries: Differentiation of the structure and development of some biochemical constituents, specially the tannins (In French). Ph.D. Thesis., Bordeaux I Univ., Bordeaux.

Park, Y. M. and K. Y. Kwon. 1999. Prevention of the incidence of skin blackening by postharvest curing procedures and related anatomical changes in 'Niitaka' pears. J. Kor. Soc. Hort. Sci. 40: 65-69.

Struckmeyer, B. E. and A. J. Riker. 1951. Wound periderm formation in white-pine trees resistant to blister rust.
Phytopathology 41: 276-281.

Wills, R. H. H. and J. K. Scott. 1982. Use of dips containing diphenylamine and edible oils to reduce soft scald of apples. HortScience 17: 964-965.

Wu, G. X., H. W. Zhou and J. M. Wang. 1992. Biochemical mechanism and substances determination of enzymic browning of Yali pear (Pyrus bretschneideri Rehd). Acta Hort. 19: 198-202.

Yamazaki, T., K. Suzuki and S. Yamaki. 1988. Physiological changes with 'Kokuhen' injury on skin of Japanese pear (Pyrus serotina Rehd.) and protection by temperature control and chemicals. J. Japan. Soc. Hort. Sci. 56: 382-390 (In Japanese with English summary).

Yun, S. D., Y. P. Hong, I. G. Mok and C. S. Lee. 2000. Factors involved with the incidence of black stain in 'Niitaka' pear during storage. J. Kor. Soc. Hort. Sci. 41: 523-525 (In Korean with English abstract). 